\title{
Kepuasan Hidup dengan Iri pada Remaja Pengguna Sosial Media
}

\author{
Sofia Kesi, Rini Hartati, Auliya Syaf \\ Fakultas Psikologi Universitas Abdurrab \\ Sofiakesi@gmail.com
}

\begin{abstract}
Abstrak
Kepuasan hidup merupakan penilaian individu terhadap dirinya dengan cara membandingkan diri dengan orang lain. Perbandingan ini akan menumbuhkan iri, dan media sosial dapat menjadi sarana mengungkapkan rasa iri. Penelitian ini bertujuan untuk melihat ada atau tidaknya hubungan kepuasan hidup dengan iri pada remaja pengguna media sosial di Pekanbaru. Metode pengumpulan data dalam penelitian ini menggunakan dua skala yaitu: skala kepuasan hidup dan skala iri. Subjek penelitian adalah remaja pengguna media sosial dengan usia 1223 tahun, berjumlah 270 subjek. Berdasarkan hasil penelitian yang dilakukan dengan teknik korelasi pearson product moment menunjukkan angka signifikansi $\mathrm{p}=0,000<(\mathrm{p}<0,01)$ hal ini menunjukkan adanya hubungan yang sangat signifikan antara variabel kepuasan hidup dengan iri pada remaja Pekanbaru.
\end{abstract}

Kata Kunci : kepuasan hidup, iri, remaja

\begin{abstract}
Life satisfaction was an individual assessment of himself by comparing himself to others. This comparison will brough up feelings of envy, and social media can be a way of expressing envy. This study aims to see whether or not there is a relationship of life satisfaction with envy among adolescent social media users in Pekanbaru. Data collection methods in this study used two scales: life satisfaction scale and envy scale. The subjects of the study were adolescent social media users aged 12-23 years, totaling 270 subjects. Based on the results of research conducted with Pearson product-moment correlation techniques showed a significant number $p=0,000<(p<0.01)$ this indicates a very significant relationship between the variables of life satisfaction with envy in Pekanbaru adolescents.
\end{abstract}

Keywords: life satisfaction, envy, teens

\section{PENDAHULUAN}

Kehadiran internet oleh masyarakat lebih dimanfaatkan sebagai media sosial, karena dengan media sosial individu bisa dengan bebas untuk berbagi dan mencari informasi serta berkomunikasi dengan orang tanpa banyak hambatan biaya, jarak dan, waktu (Soliha, 2015). Media sosial yang paling sering di kunjungi di Indonesia, meliputi facebook dengan presentase 50,7\%, instagram dengan 17,8\%, dan Youtube 15,1) (APJII [Asosiasi Penyedia Jasa Internet Indonesia], 2018). Media sosial merupakan situs yang dapat membantu seseorang untuk membuat sebuah profil dan kemudian dapat menghubungkan dengan pengguna lainnya yang memungkinkan pengguna untuk terhubung menggunakan profil pribdi atau akun pribadi contoh jenis aplikasi media sosial seperti facebook, twitter, instagram, youtube dan lainnya (Boyd \& Ellison, 2007).

Adapun fungsi dari media sosial adalah dapat menjadi media komunikasi, presentasi diri (menampilkan diri) baik itu secara real maupun virtual (Boyd \& Ellison, 2007). Akan tetapi, fungsi dari media sosial menunjukkan dampak buruk yang signifikan misalnya melakukan perbandingan sosial keatas, bahayanya dapat menurunkan kesejahteraan psikologi pengguna (Burke, Marlow, 2010). Perbandingan sosial ke atas dapat menimbulkan iri yaitu 
munculnya emosi dan perasaan negatif akibat dari kelebihan orang lain (Appel, Crusius, \& Gerlach, 2015).

Menurut Faturochman (2006) iri terjadi ketika individu berkeinginan untuk memeroleh keuntungan sama seperti yang diperoleh orang lain atau teman. Iri dapat dibagi menjadi dua keadaan yang berbeda positif dan negatif, iri yang negatif adalah iri yang membuat individu berkeinginan untuk merusak keadan atau kesenangan orang lain, sedangkan iri yang positif yaitu individu termotivasi bergerak maju untuk mendapatkan sesuatu yang diinginkan (van de Ven, Zeelenberg, \& Pieters, 2009).

Hasil penelitian yang dilakukan oleh Krasnova, Wenninger, Widjaja, dan Buxmann (2013) melaporkan iri sebagai ancaman tersembunyi bagi kepuasan hidup pengguna media sosial. Kepuasan hidup berpatokan penilaian individu pada standar yang telah di tetapkannya (Aswin \& Ramdhani, 2017). Menurut Park (2004) kepuasan hidup memiliki banyak peran positif dalam tahap perkembangan remaja. Remaja dengan kepuasan hidup tinggi dalam menghadapi peristiwa yang menekan memunculkan tingkah laku bermasalah seperti iri negatif (sadar) menjadi lebih rendah(Suldo \& E scott Huebner, 2004). Namun keterarikan remaja secara berlebihan pada media sosial justru menimbulkan atau meningkatkan iri dan dapat berpengaruh pada kepuasan hidup (Aswin \& Ramdhani, 2017; Krasnova et al., 2013). APJII (2018) mengungkapkan bahwa pengguna media sosial di Indonesia pada umumnya adalah remaja, dengan umur 19 - 34 tahun dengan 49,52\%. Serta 75,50\% dengan umur 13-18 tahun. Disisi lain, Tandoc, Ferrucci, dan Duffy (2015) bahwa penggunaan media sosial dapat berdampak pada emosi negatif seperti iri, bahkan depresi. Berbagai uraian di atas mengindikasikan iri dapat mengancam kepuasan hidup individu, namun demikian keberadaan media sosial berdampak pada munculnya perbandingan sosial yang dapat menimbulkan emosi negatife, seperti iri. Hal ini kemudian menjadi dasar rumusan bagaimana "Hubungan antara Kepuasan Hidup dengan Iri Pada Remaja pengguna Media Sosial”

\section{METODE}

Subjek dalam penelitian ini adalah remaja di Pekanbaru yang memiliki akun media sosial dengan rentang usia 12-23 tahun. Pengambilan sampel menggunakan teknik accidental sampling. Alat ukur yang digunakan dalam penelitian ini menggunakan skala kepuasan hidup dan skala iri dengan menggunakan model skala likert, dengan respon jawaban dari 1 (sangat sesuai) sampai 5 (sangat tidak sesuai). Skala kepuasan hidup dibuat berdasarkan lima aspek, meliputi keinginan untuk merubah hidup, kepuasan terhadap hidup saat ini, kepuasan hidup di masa lalu, kepuasan terhadap kehidupan di masa depan, dan penilaian orang lain terhadap kehidupan seseorang (Diener, Oishi, \& Lucas, 2003). Koefisien reliabilitas $\alpha$ skala kepuasan hidup yaitu 0,796 dengan jumlah aitem 23. Skala iri dibuat berdasarkan aspek kognitif dan emosional (Ninivaggi, 2010). Koefisien reliabilitas $\alpha$ skala gaya hidup hedonis yaitu sebesar 0,928 dengan jumlah aitem 15 pernyataan. 


\section{HASIL}

Tabel 1. Gambaran Hipotetik variabel kepuasan hidup

\begin{tabular}{ccccccccc}
\hline \multirow{2}{*}{ Variabel } & \multicolumn{4}{c}{ Empirik } & \multicolumn{4}{c}{ Hipotetik } \\
\cline { 2 - 9 } & Maks & Min & Rerata & SD & Maks & Min & Rerata & SD \\
\hline Kepuasan Hidup & 69 & 36 & 54,1 & 6,7 & 75 & 15 & 45 & 10 \\
Iri & 94 & 25 & 50,7 & 13,1 & 115 & 23 & 69 & 15,3 \\
\hline
\end{tabular}

Berdasarkan tabel 1 di atas, jumlah skor rata-rata kepuasan hidup (mean : 54,1, SD : 6,7 ) empirik lebih besar dari pada jumlah skor rata-rata (mean : 45, SD : 10) hipotetik pada skala kepuasan hidup $(54,1>45)$, hal ini menunjukkan bahwa kepuasan hidup pada remaja di Pekanbaru yang diteliti tinggi sedangkan, jumlah skor rata-rata (mean : 50,7 SD : 13,1) empirik lebih kecil dari pada jumlah skor rata-rata (mean : 69, SD : 15,3) hipotetik pada skala iri $(50,7<69)$, hal ini menunjukkan bahwa iri pada remaja di Pekanbaru yang diteliti rendah.

Tabel 2. Kategorisasi Kepuasan Hidup Remaja pengguna media sosial di Pekanbaru

\begin{tabular}{cccc}
\hline Kategori & Skor Interval & Frekuensi & Persentase (\%) \\
\hline Rendah & $\mathrm{X}<35$ & 5 & $1,9 \%$ \\
Sedang & $35 \leq \mathrm{X}<55$ & 140 & $51,9 \%$ \\
Tinggi & $\mathrm{X} \geq 55$ & 125 & $46,3 \%$ \\
\hline Jumlah & & $\mathbf{2 7 0}$ & $\mathbf{1 0 0 \%}$ \\
\hline
\end{tabular}

Berdasarkan kategori di atas, hasil perhitungan menunjukkan dari 270 sampel penelitian terdapat 5 orang $(1,9 \%)$ kepuasan hidup kategori rendah, 140 orang $(51,9 \%)$ kepuasan hidup pada kategori sedang, sebesar 125 orang $(46,3 \%)$ dalam kategori rendah.

Tabel 3. Kategorisasi iri (Y)

\begin{tabular}{cccc}
\hline Kategori & $\begin{array}{r}\text { Skor } \\
\text { Interval }\end{array}$ & Frekuensi & Persentase (\%) \\
\hline Rendah & $\mathrm{X}<54$ & 181 & $67 \%$ \\
Sedang & $54 \leq \mathrm{X}<84$ & 88 & $32,6 \%$ \\
Tinggi & $\mathrm{X} \geq 84$ & 1 & $0,4 \%$ \\
\hline Jumlah & & $\mathbf{2 7 0}$ & $\mathbf{1 0 0 \%}$ \\
\hline
\end{tabular}

Berdasarkan tabel 3 di atas, hasil perhitungan menunjukkan dari 270 sampel penelitian terdapat 181 orang $(67 \%)$ iri pada remaja pengguna media sosial kategori rendah, 88 orang $(32,6 \%)$ iri kategori sedang, dan untuk kategori tinggi sebesar 88 orang $(32,6 \%)$.

Data asumsi dari variabel menggunakan uji normalitas Kolmogorov smirnov dengan nilai $p$ sebesar 0,200 ( $>0,05)$, dengan demikian dapat disimpulkan bahwa sebaran data kepuasan hidup dan iri berdistribusi normal. Sedang hasil uji linieritas menunjukkan bahwa $\mathrm{F}=161,9$ dan $p=0,000(<0,05)$, dengan demikian dapat dikatakan bahwa kepuasan hidup dan iri memiliki hubungan linear. Setelah uji asumsi, kemudian dilakukan uji hipotesis dengan menggunakan product moment. Hasil menunjukkan signifikansi 0,000 $\mathrm{r}=-0,596$, dari tabel 6 di ketahui bahwa ada hubungan signifikan antara kepuasan hidup dengan iri, dengan korelasi negatif. Dengan kata lain semakin tinggi kepuasan hidup maka semakin rendah Iri, begitupun sebaliknya semakin rendah kepuasan hidup semakin tinggi iri. 
Tabel 4. Uji Hipotesis

\begin{tabular}{cccc}
\hline Variabel & sig & Korelasi & Keterangan \\
\hline Kepuasan hidup dan Iri & 0,000 & $-0,596^{* *}$ & Sig \\
\hline
\end{tabular}

\section{PEMBAHASAN}

Temuan penelitian mengungkapkan bahwa ada hubungan antara kepuasan hidup terhadap iri pada remaja pengguna media sosial di Pekanbaru. Hal ini sejalan dengan penelitian (Diener et al., 2003) yang menunjukkan da hubungan antara iri dengan kepuasan hidup individu, sementara enelitian ini sejalan dengan penelitian Aswin dan Ramdhani (2017) juga menunjukkan bahwa ada hubungan signifikan antara kepuasan hidup dengan iri di media sosial. Laporan serupa juga ungkapkan oleh Kross et al., (2013) yang mengungkapkan bahwa mengakses media sosial seperti Facebook secara terus menerus dapat menurunkan kesejahteraan subjektif dan kepuasan hidup, baik dalam aspek afektif maupun kognitif. Pendapat ini sejalan dengan apa yang di sampaikan oleh Armalita dan Helmi (2018) bahwa individu dengan iri dan melihat lebih banyak sosial media akan mengalami penurunan kepuasan.

Dalam menilai kepuasan hidup seseorang didefinisikan sebagai penilaian subjektif evaluasi kognitif berdasarkan standar yang telah ditentukan oleh individu (Gilman, Huebner, \& Buckman, 2009). Jika penilaian ini mengarah pada kemampuan individu sendiri makan akan menjadi dasar penilaian yang baik. Namun individu sering menggunakan teori upward social comparison, individu cenderung melakukan perbandingan negatif yang dapat berdampak pada munculnya emosi negatif seperti iri (Appel et al., 2015; Smith, 2000).

Cohen-Charash (2009) menyebutkan bahwa pada saat individu merasa iri, emosi tidak menyenangkan akan muncul dari perbandingan. Pada awalnya remaja akan melakukan pengamatan terhadap postingan orang lain dimedia sosial yang penggunanya cenderung memposting hal-hal meyenangkan saja dalam kehidupannya (Hu, Manikonda, \& Kambhampati, 2013). Iri muncul ketika individu mulai membandingkan dirinya dan individu lain di sosial media. Iri yaitu emosi negatif terhadap seseorang sehingga mengiginkan hasil yang diperoleh oleh orang lain seperti kualitas unggul, prestasi (Cohen-Charash \& Mueller, 2007). Yang pada akhirnya dapat mempengaruhi kepuasan hidup seseorang(Krasnova et al., 2013). Semakin sering individu melihat postingan di media sosial seperti facebook, akan semakin memperkuat iri dan kemudian menurunkan kepuasan hidup (Krasnova et al., 2013).

Aswin dan Ramdhani (2017) menunjukkan hasil bahwa dampak negatif dari penggunaan media sosial adalah munculnya iri akibat dari perbandingan sosial keatas. Iri terjadi karena empat kondisi, yaitu individu yang merasa iri memiliki kesamaan atribut dengan target iri, atribut yang dimiliki oleh target iri merupakan sesuatu yang sangat penting bagi diri individu, atribut yang diinginkan sulit dicapai, serta adanya perasaan ketidakadilan subjektif (Smith, 2004). Iri dapat menyebabkan kerusakan signifikan pada kesejahteraan pengguna dan memengaruhi kepuasan hidup. Penelitian dari psikologi sosial mengungkapkan bahwa iri hati dapat menyebabkan frustrasi, penderitaan mental dan bahkan depresi (Krasnova et al., 2013). Iri juga memiliki dampak buruk dalam relasi sosial yaitu intrapersonal maupun interpersonal (Faturochman, 2006).

Menurut penelitian Armalita dan Helmi (2018), Envy on Social Media: The Deservingness Theory of Emotion membuktikan bahwa aktivitas memantau informasi tentang orang lain di jejaring sosial tidak secara langsung menurunkan kepuasan hidup pengguna namun, didahului oleh reaksi emosional yang negatif yaitu emosi iri terhadap postingan orang 
tersebut akibat dari penilaian deservingness rendah, pengguna lain di anggap lebih cenderung mengunggah foto dan video yang menyenangkan dalam kehidupannya. Temuan sebelumnya menunjukkan bahwa iri dapat berdampak negatif pada individu karena melakukan perbandingan (Adrianson \& Ramdhani, 2014; Krasnova et al., 2013; Lin \& Utz, 2015; Smith \& Kim, 2007), namun demikian iri juga dapat memberikan dampak positif (Rodriguez Mosquera, Parrott, \& de Mendoza, 2010; Smith, 2000). Iri positif merupakan jenis iri sadar yang secara bijak dapat dikelola menjadi positif (Ninivaggi, 2010), seperti meningkatkan kepercayaan diri (Rodriguez Mosquera et al., 2010). Sebagai mana yang di ungkap oleh (Ninivaggi, 2010) bahwa iri di bagi atas iri sadar dan tidak sadar. Iri tidak sadar merupakan iri yang tidak di akui oleh individu, sehingga menimbulkan dampak negatif, sementara Iri sadar merupakan iri yang diterima oleh individu sehingga dapat dikelola secara positif. Pedapat ini perlu di pertimbangkan untuk penelitian selanjutnya sebagai bagian dari evaluasi penelitian yang dapat menyeimbangkan penilaian iri tidak hanya fokus pada yang negatif tapi juga positif.

\section{SIMPULAN}

Hasil penelitian menunjukkan adanya hubungan yang signifikan antara kepuasan hidup dengan iri pada remaja Pekanbaru. Temuan ini menggambarkan bahwa rasa iri yang di dapatkan dari penggunaan sosial media dapat berdampak pada kondisi psikis individu. Iri dapat menjadi faktor yang menurunkan kepuasan hidup. Kecendrung penilaian iri yang di dasarkan pada perbandingan sosial ke atas ataupun teori upward comparison akan menyebabkan iri mengarahkan individu pada kondisi negatif. Temuan ini sejalan dengan penelitian sebelumnya yang menyebutkan bahwa iri dapat berdampak negatif pada kepuasan hidup individu, terutama pada sosial media.

\section{DAFTAR PUSTAKA}

Adrianson, L., \& Ramdhani, N. (2014). Why you and not me? Expressions of envy in Sweden and Indonesia. International Journal of Research Studies in Psychology, 3(3), 43-65. https://doi.org/10.5861/ijrsp.2014.743

APJII [Asosiasi Penyedia Jasa Internet Indonesia]. (2018). Penetrasi \& Profil Perilaku Pengguna Internet Indonesia. Apjii. Retrieved from www.apjii.or.id

Appel, H., Crusius, J., \& Gerlach, A. L. (2015). Social comparison, envy, and depression on facebook: A study looking at the effects of high comparison standards on depressed individuals. Journal of Social and Clinical Psychology, 34(4), 277-289. https://doi.org/10.1521/jscp.2015.34.4.277

Armalita, R., \& Helmi, A. F. (2018). Iri di Situs Jejaring Sosial: Studi tentang Teori Deservingness. Jurnal Psikologi, 45(3), 218. https://doi.org/10.22146/jpsi.33313

Aswin, I. M., \& Ramdhani, N. (2017). Hubungan antara penggunaan pasif dan iri dengan kepuasan hidup pengguna situs jejaring sosial. Universitas Gadjah Mada. https://doi.org/10.13140/RG.2.2.30615.06564

Boyd, D. M., \& Ellison, N. B. (2007). Social network sites: Definition, history, and scholarship. Journal of Computer-Mediated Communication, 13(1), 210-230. https://doi.org/10.1111/j.1083-6101.2007.00393.x 
Burke, Marlow, L. (2010). The weight of structural violence: Syndemic stress and obesity among Black urban youth in the US. Proceedings of the SIGCHI Conference on Human Factors in Computing Systemss, 7, 1909-1912. https://doi.org/" "

Cohen-Charash, Y. (2009). Episodic envy. Journal of Applied Social Psychology, 39(9), 2128 2173. https://doi.org/10.1111/j.1559-1816.2009.00519.x

Cohen-Charash, Y., \& Mueller, J. S. (2007). Does perceived unfairness exacerbate or mitigate interpersonal counterproductive work behaviors related to envy? Journal of Applied Psychology, 92(3), 666-680. https://doi.org/10.1037/0021-9010.92.3.666

Diener, E., Oishi, S., \& Lucas, R. E. (2003). Personality, Culture, and Subjective Well-Being: Emotional and Cognitive Evaluations of Life. Annual Review of Psychology, 54(1), 403425. https://doi.org/10.1146/annurev.psych.54.101601.145056

Faturochman. (2006). Iri dalam Relasi Sosial. Jurnal Psikologi, 33(1), 1-16. https://doi.org/10.22146/jpsi.7956

Gilman, R., Huebner, S., \& Buckman, M. (2009). Life satisfaction. In S. J. Lopez (Ed.), The Encyclopedia of Positive Psychology. NJ: Wiley.

Hu, Y., Manikonda, L., \& Kambhampati, S. (2013). What we Instagram. Frontiers of Mathematics in China, 12(1), 247-260. https://doi.org/10.1007/s11464-016-0589-9

Krasnova, H., Wenninger, H., Widjaja, T., \& Buxmann, P. (2013). Envy on Facebook: A Hidden Threat to Users ' Life Satisfaction?, (March), 1-16.

Kross, E., Verduyn, P., Demiralp, E., Park, J., Lee, D. S., Lin, N., ... Ybarra, O. (2013). Facebook Use Predicts Declines in Subjective Well-Being in Young Adults. PLoS ONE, 8(8), 1-6. https://doi.org/10.1371/journal.pone.0069841

Lin, R., \& Utz, S. (2015). The emotional responses of browsing Facebook: Happiness, envy, and the role of tie strength. Computers in Human Behavior, 52, 29-38. https://doi.org/10.1016/j.chb.2015.04.064

Ninivaggi, F. J. (2010). Envy theory: perspectives on the psychology of envy. Lanham: Rowman \& Littlefield Publishers, INC. https://doi.org/10.5860/choice.48-5388

Park, N. (2004). The Role of Subjective Well-Being in Positive Youth Development. Annals of the American Academy of Political and Social Science, 591, 25-39. https://doi.org/10.1177/0002716203260078

Rodriguez Mosquera, P. M., Parrott, W. G., \& de Mendoza, A. H. (2010). I Fear Your Envy, I Rejoice in Your Coveting: On the Ambivalent Experience of Being Envied by Others. Journal of Personality and Social Psychology, 99(5), 842-854. https://doi.org/10.1037/a0020965

Smith, R. H. (2000). Assimilative and Contrastive Emotional Reactions to Upward and Downward Social Comparisons. Handbook of Social Comparison, 173-200. https://doi.org/10.1007/978-1-4615-4237-7_10

Smith, R. H. (2004). Envy and Its Transmutations. In L. T. \& C. Leach (Ed.), The Social Life of Emotion (Studies in Emotion and Social Interaction) (pp. 43-63). Cambridge: 
Cambridge University Press. https://doi.org/10.1017/cbo9780511819568.004

Smith, R. H., \& Kim, S. H. (2007). Comprehending envy. Psychological Bulletin, 133(1), 4664. https://doi.org/10.1037/0033-2909.133.1.46

Soliha, S. F. (2015). Tingkat Ketergantungan Pengguna Media Sosial Dan Kecemasan Sosial. JURNAL INTERAKSI, 4(1), 1-10. https://doi.org/10.14710/interaksi,4,1,1-10

Suldo, S. M., \& E scott Huebner. (2004). Does life satisfaction moderate the effects of stressful life events on psychopathological behavior during adolescence? School Psychology Quarterly, 19(2), 93-105. https://doi.org/10.1521/scpq.19.2.93.33313

Tandoc, E. C., Ferrucci, P., \& Duffy, M. (2015). Facebook use, envy, and depression among college students: Is facebooking depressing? Computers in Human Behavior, 43, 139-146. https://doi.org/10.1016/j.chb.2014.10.053

van de Ven, N., Zeelenberg, M., \& Pieters, R. (2009). Leveling Up and Down: The Experiences of Benign and Malicious Envy. Emotion, 9(3), 419-429. https://doi.org/10.1037/a0015669 